\title{
The Potential Use of Patchouli Root to Prevent Mosquito Bite
}

\author{
Fardhiasih Dwi Astuti $^{1 *}$, Putri Puspitasari ${ }^{1}$ \\ ${ }^{I}$ Public Health, Ahmad Dahlan University, Prof. Dr. Soepomo, Janturan, Umbulharjo, Yogyakarta 55166, Indonesia \\ "Corresponding author.Email: fardhiasih.dwiastuti@ikm.uad.ac.id
}

\begin{abstract}
Mosquitoes are spread all over the world, mosquito-borne diseases are serious health problems. Mosquito coil can prevent contact between mosquitos and humans. Patchouli (Pogostemon cablin B.) contains active ingredients that can serve as insecticide which are saponin, flavonoid, and essential oils. In this study, the effectiveness of mosquito coil made from patchouli waste against Aedes aegypti was analyzed. This research was an experimental design. The object of the research was female mosquitoes of Ae. aegypti age 2-5 days and was fed with $10 \%$ sugar solution. Mosquito coil test was done by observing the mortality of mosquitoes in 24 hours after exposure to burning mosquito coil, with three replications. One way Anova and probit analysis were used to analyse the data. The mortality rate of Ae. aegypti due to mosquito coil made from patchouli waste at $6.25 \%, 10 \%$, and $16.67 \%$ concentrations was $45 \%-91 \%$. The mortality rate of Ae. aegypti at $16.67 \%$ concentration of patchouli waste showed no significant difference compared to transfluthrin $0.03 \%$ as positive control (p value >0.05). KT 50 and KT 95 on mosquito coil patchouli waste were faster at $16.67 \%$ concentration, ie 34.38 minutes and $58.09 \mathrm{~min}$, while on transfluthrin $0.03 \%$ it took $10.03 \mathrm{~min}$ and $33.74 \mathrm{~min}$. There is no difference between the mean mortality rate of mosquito due to mosquito coil made from patchouli waste at $16.67 \%$ concentration and transfluthrin $0,03 \%$.
\end{abstract}

Keywords: patchouli waste, mosquito coil, Aedes aegypti

\section{INTRODUCTION}

Mosquito can be found all around the word. Mosquitoborne diseases are global public health problem [1]. Dengue, Zika, Chikungunya are transmitted by Aedes sp. Malaria is transmitted by Anopheles, and Filaria is transmitted by Anopheles, Culex or Mansonia [2, 3]. Mosquito-borne diseases can be prevented by controlling mosquito and preventing contact between human and vector [4]. Bed nets, insecticide sprays, and mosquito coils can be used to prevent contact and mosquito bite [3,5].

The insecticides used to control mosquito contain active ingredients such as organophosphate, carbamate, and pyrethroid which can lead to mosquito developing resistance to the afore mentioned active ingredients [6]. Organochlorine could pollute the air, lake or water. Pesticide pollution in the environment causes endocrine disruption. Exposure to low amount of dose for a long period of time can increase the risk to human health such as immune suppression, hormone disruption, diminished. intelligence, reproductive abnormalities, and cancer [7, 8]. Organochlorine has been banned from circulating in Indonesia [9]. Pyrethroid insecticide such as d-cis transallethrin is a common active ingredient in mosquito coils with concentration of 0.25 . In addition, mosquito coils contain heavy metals such as $\mathrm{Cr}, \mathrm{Co}, \mathrm{As}, \mathrm{Cd}$, and $\mathrm{Pb}$. [10] Mosquito coils release a considerable amount of fine to ultrafine particulate matter (PM) which can be deposited in the lungs. Exposure to PM and its associated chemicals may contribute to acute and chronic respiratory diseases, such as pneumonia and asthma, irritated skin, coughing, dizziness, nausea, vomiting, and even passing out as well as various toxic chemical responses [11]. The disadvantage of using artificial insecticides is that the mode of action is not selective which can harm other organisms. Pyrethroids are toxic at invertebrates and fish at very low concentration [12].

One way to avoid the use of artificial insecticide products is by using natural insecticides. Many plants contain essential oil which can repell insects [13]. Patchouli plants (Pogostemon cablin) is one natural source that can be used as repellent. The plant has essential oil content which can be obtained through the process of extraction. Patchouli from Indonesia is most in the world [14]. Essential oil from patchouli can protect from mosquito bite for 2-4 hours [15]. After refining the oil, patchouli leaves (Pogostemon cablin) will become solid waste that can be used to make mosquito coils because it still contain active ingredients such as saponins, flavonoids, and essential oils. The essential components of the essential oils are patchoulol, a-guaiene, a and $\beta$ patchoulene, seychellene, and a-bulnesene. sesquiterpenes and patchouli alcohol. The essential oils of patchouli plants contain sesquiterpene and patchouli alcohol (oxygenated terpene) consisting of benzol decide, eugenol benzoate, aldehyde syndrome, alcohol, and semicarbazone 
[16]. Sesquiterpene and patchouli alcohol are known to have insecticidal properties [17]. The waste from patchouli extraction can be made into mosquito coil. The aim of our study is to analyse the potency of mosquito coil made from the waste of patchouli.

\subsection{Materials and Methods}

This study was conducted in the Entomology Laboratory of Faculty of Public Health, Ahmad Dahlan University at March 2016. The test was conducted in a glass chamber sized $70 \times 70 \times 70 \mathrm{~cm}$. The research is experimental with post-test only control group design. The study used Aedes aegypti female mosquitoes age 2-5 days and fed with $10 \%$ sucrose solution that have been reared in the Entomology Laboratory of Ahmad Dahlan University. Twenty-five mosquitoes were used in each experiment. The temperature used was $25^{\circ} \mathrm{C}-29{ }^{\circ} \mathrm{C}$ with humidity of 70-90\%

Mosquito coil was made from Patchouli waste, sawon wood, and arabic gum. Mosquito coil was prepared manually until it dried out. The concentrations of mosquito coil were at $6.25 \%, 10 \%$, and $16.67 \%$. Control without patchouli waste was also prepared.

The mosquito coil test process started by testing the negative control on the glass chamber, then 25 mosquitoes were inserted into the glass chamber for 60 minutes, paralysis of mosquitoes were observed every 10 minutes for one hour. Assessment of knockdown was made after 60 minutes. After exposure, the mosquitoes were transferred to a clean cup and fed with sucrose solution, then placed back in a room with temperature between 25 ${ }^{\circ} \mathrm{C}-29{ }^{\circ} \mathrm{C}$ and $70 \%-90 \%$ humidity, then the mortality of the mosquitoes after $24 \mathrm{hr}$ post-treatment was observed. Bioefficacy data were subjected to probit analysis using a computer program to determine KT 50. Data from the experiment on sublethal effects were analysed with analysis of variance. Mean was separated with the least significant difference (Bonferroni) statistical analysis performed using a statistical analysis computer program [18].

\subsection{Our Contribution}

This paper presents the benefits of patchouli as Mosquito Coils. Patchouli is a plant that contains active ingredients that can kill mosquitoes. The results of the experiment showed that the ability of mosquito coils made from patchouli could match the killing power of mosquito repellent made from transfluthrin

\subsection{Paper Structure}

This paper consists of the following sections, the first part is the introduction. The second part shows the killing power of patchouli-based mosquito coils compared to positive control. The next section shows how long it takes for mosquito coils to kill mosquitoes. The last section is the conclusion.

\section{RESULTS AND DISCUSSION}

The efficacy of mosquito coil made from patchouli waste and the average number of mosquito mortality due to mosquito coil at the concentrations of $6.25 \%, 10 \%$, $16.67 \%$, negative control, and positive control (transfluthrin $0.03 \%$ ) (Table 1).

Patchouli mosquito coil at the concentration of $16.67 \%$ results in mosquito up to $91 \%$ deaths. The mortality of mosquito after exposure to patchouli coil at $16.67 \%$ concentration is not significantly different to positive control. Increase in concentration also increase the mortality rate.

The knockdown time (KT 50) of mosquito exposed to mosquito coil made from patchouli waste with the concentrations of $6.25 \%, 10 \%$, and $16.67 \%$ were 44.80 min, $41.00 \mathrm{~min}$, and $34.38 \mathrm{~min}$, respectively. The KT 50 of positive control (transfluthrin $0.03 \%$ ) was $10.03 \mathrm{~min}$ (Table 2).

Various plants contain essential oils that can be used as insecticides such as pyrethrum which is common in mosquito coil formulations [19]. Pyrethrin quick knockdown time on flying insects, especially on mosquitoes and houseflies. The mode of action is by attaching to insect nervous system at the Na channels [20]. The active ingredient in patchouli is sesquiterpene patchoulol [16]. The major compounds were patchoulol

Table 1 Mortality of Aedes aegypti due to mosquito coil made from patchouli waste 24 hours after exposure abbott formula correction

\begin{tabular}{|c|c|c|c|c|}
\hline Dose \% w/w & Average Mortality SD & Mortality (\%) & P value & $\begin{array}{c}\text { P value positive } \\
\text { control }\end{array}$ \\
\hline 6.25 & $13 \pm 0.57$ & 45 & 0.000 & 0.000 \\
\hline 10 & $17 \pm 1.52$ & 64 & 0.000 & 0.000 \\
\hline 16.67 & $23 \pm 1.00$ & 91 & 0.000 & 0.493 \\
\hline Negative Control & $3 \pm 1.52$ & & & \\
\hline Positive Control & $25 \pm 0.00$ & 100 & & \\
\hline
\end{tabular}


Table 2 Knockdown time of mosquito coil made from patchouli waste

\begin{tabular}{|l|c|c|c|}
\hline Dose \% w/w & KT 50 CI 95 \% (minutes) & KT 95 CI 95\% (minutes) & P-value \\
\hline 6.25 & $44.85(41.17-48.64)$ & $68.56(63.70-74.60)$ & 0.00 \\
\hline 10 & $41.05(37.38-44.78)$ & $64.76(60.03-70.62)$ & 0.00 \\
\hline 16.67 & $34.38(30.71-38.02)$ & $58.09(53.54-63.67)$ & 0.00 \\
\hline Positive Control & $10.03(5.09-14.51)$ & $33.747(29.14-38.96)$ & 0.00 \\
\hline
\end{tabular}

Increased patchouli concentration requires a shorter time to kill mosquitoes

(36.60\%) followed by $\alpha$-bulnesene $(13.95 \%)$, and $\alpha$ guaiene $(11.96 \%)$ [21]. Waste from refining patchouli oil can functions as anti-mosquito respiratory toxin. Essential oils enter into the body of mosquito through respiratory system and then transported to the nervous system. The place where the poison. The mode of action of saponin is by binding itself to free sterols in the digestive tract where the sterol itself is a substance that acts as an eczema hormone precursor. The decrease in the number of free sterols in the body of the mosquito will consequently interfere with the absorption of food. While the way flavonoids works are by inhibiting respiration and causing damage to barrier permeability in the respiratory system. This situation will reduce tissue perfusion in the respiratory system resulting in respiratory failure in mosquitoes [22].

An increase in the concentration of patchouli waste can increase the mortality rate Aedes aegypti mosquitoes due to higher content of active ingredients such as saponins, flavonoids, and essential. This is in line with a research conducted by Rianti[11] which has one of the same active ingredients as the patchouli flavonoid as an anti-mosquito substance. The number of Aedes aegypti mosquito deaths increased by increasing the concentration from 5\% to $10 \%$. Patchouli waste can be used to make commercial products for pest management. Biopesticide is less toxic, degradable, and environmentally friendly [13].

Post hoc analysis (Bonferroni test) showed that there was a significant difference in mosquito mortality rate between mosquito coil made from patchouli waste at the concentrations of $6.25 \%$ and $10 \%$ with transfluthrin $0.03 \%$ as positive control. The comparison between mosquito coil made from patchouli waste at $16.67 \%$ concentration with transfluthrin $0.03 \%$ showed that there was no significant difference in mosquito mortality rate, so it can be said that the effectivity of mosquito coil made from patchouli waste at $16.67 \%$ concentration in killing mosquitoes is almost the same as transfluthrin $0.03 \%$.

Based on the results, patchouli waste can be used as an alternative to synthetic chemicals for controlling mosquito. In addition, in terms of health safety, anti-mosquito products made from patchouli waste are easier and quicker to decompose in nature because the material is natural, while transfluthrin $0.03 \%$ active material is not as easy to decompose in nature because the material comes from artificial chemicals. Chemical pesticides can also lead to insects developing resistance [23].
Based on the results of Probit analysis, decreasing paralysis time or Knockdown Time along with increasing the concentration of patchouli waste resulted in less time required to cripple mosquitoes if there are higher amount of active ingredients in the mosquito coil. The higher amount of active ingredients found in anti-mosquito fuel can increase the killing power. This is supported by the result of positive control that showed $0.03 \%$ transfluthrin is stronger and quicker to paralyze the mosquitoes than natural active ingredients which are saponins, flavonoids, and essential oils.

Previous studies showed that patchouli oil with concentration of $15 \%$ sprayed on natural anti-mosquito fuel have KT 50 and KT 90 values that decrease when concentration is increased. The KT 50 and KT 90 results showed that at $7.5 \%$ concentration the KT 50 was 52.91 min and KT 90 was 87.69 minutes, at $10 \%$ concentration KT 50 was 44.72 min and KT 90 was $74.62 \mathrm{~min}$, and at $15 \%$ KT 50 was 37.06 minutes and KT 90 was $67.20 \mathrm{~min}$ [19]. In this study, the KT 50 at concentration $16.67 \%$ is 34.38 minute.

When compared with the results of the study, at the same concentration of $10 \%$, the KT 50 in this study is $41.05 \mathrm{~min}$, slightly faster than the $10 \%$ concentration in the previous study. This comparison indicates that the results of this study are similar to the study conducted by Phal et al. [19].

\section{CONCLUSION}

The bioefficacy test showed that mosquito coil at $16.67 \%$ concentration has the same Aedes aegypti mortality rate as transfluthrin $0.03 \%$. Knockdown time 50 of mosquito coil made from patchouli waste at $16.67 \%$ concentration is $34.38(30.71-38.02)$ min.

\section{ACKNOWLEDGMENT}

The authors are grateful to the director of Faculty of Public Health Laboratory, Ahmad Dahlan University, and the staff for permission to use the facilities. 


\section{REFERENCE}

[1] WHO. Dengue guidelines for diagnosis, treatment, prevention, and control, WHO, 2009. https://apps.who.int/iris/bitstream/ha ndle/10665/44188 /9789241547871_eng.pdf?sequence=1 \&isAllowed $=\mathrm{y}$

[2] J. Popovici, L.A. Moreira, A. Poinsignon, I. Iturbe-ormaetxe, D. Mcnaughton, S.L.O. Neill, Assessing key safety concerns of a Wolbachiabased strategy to control dengue transmission by Aedes mosquitoes, Mem. Inst. Oswaldo Cruz. 105 (8) (2010) 957-964. DOI: https://doi.org/10.1590/S0074-027620100008000 02

[3] J. Hemingway, H. Ranson, Insecticide resistance in insect vectors of human disease, Annu. Rev. Entomol. 45 (1) (2000) 371-391. DOI: https://doi.org/10.1146/annurev.ento.45.1.371

[4] L. Eisen, B.J. Beaty, A.M.Y.C. Morrison, Proactive vector control strategies and improved monitoring and evaluation practices for dengue prevention. J. Med. Entomol. 46 (6) (2009) 12451255. DOI: https://doi.org/10.1603/033.046.0601

[5] D. Roiz, A.L. Wilson, T.W. Scott, D.M. Fonseca, F. Jourdain, P. Müller, et al., Integrated Aedes management for the control of Aedes-borne diseases. Plos. Negl. Trop. Dis. 12 (12) (2018) $\mathrm{e} 0006845$.

DOI: https://doi.org/10.1371.journal.pntd.0006845

[6] RI Ministry of Health, Guidlines for the use of insecticides (pesticides) in vector control, Jakarta, RI Ministry of Health, 2012

[7] W. Aktar, D. Sengupta, A. Chowdhury, Impact of pesticides use in agriculture: Their benefits and hazards. Interdiscip. Toxicol. 2 (1) (2009) 1-12. DOI: https://doi.org/10.2478/v10102-009-0001-7

[8] M.M. Rahman, Insecticide substitutes for DDT to control mosquitoes may be causes of several diseases. Environ. Sci. Pollut. Res. 20 (4) (2012) 2064-9. DOI: https://doi.org/10.1007/s11356-0121145-0

[9] M.C. Yuantari, Impact of organoclorine pesticides on human health, environment, and its handling. In: Proceeding of National Seminar on the Role of Public Health in Achieving MDG'S in Indonesia, 2011, pp. 187-199.

[10] J. Kasumba, B. Hettick, A. French, J.K. Wickliffe, M.Y. Lichtveld, W.B. Hawkins, Analysis of pesticides and toxic heavy metals contained in mosquito coils, B. Environ. Contam. Tox. 97(5) /s00128-016-1938-9

[11] E.D.D. Rianti, Mechanism of exposure to electric anti-mosquito drugs and anti-mosquito coils to the rat lungs, Inovation, 19(2) (2017) 58-68.

[12] K. Palmquist, J. Salatas, A. Fairbrother, Pyrethroid Insecticides: Use, Environmental Fate, and Ecotoxicology. In: Insecticides-Advances in Integrated Pest Management, 2012,

https://www.intechopen.com/books/insecticidesadvances-in-integrated-pestmanagement/ pyrethroid-insecticides-use-environmental-fateand-ecotoxicology

[13] M. Pant, S. Sharma, S. Dubey, S.N. Naik, P.K. Patanjali, Utilization of biodiesel by-products for mosquito control. J. Biosci. Bioeng. 121(3) (2016) 299-302. DOI: http://dx.doi.org/10.1016/j.jbiosc.2015.07.0 10

[14] M. Anitha, Agro-Processing Of Patchouli (Pogostemon Cablin Benth.) For Efficient Essential Oil Extraction, University of Agricultural Sciences, Bangalore, 2008

[15] Y. Trongtokit, Y. Rongsriyam, N. Komalamisra, C. Apiwathnasorn, Comparative repellency of 38 essential oils against mosquito bites. Phyther Res, 19 (4) (2005) 303-309. DOI: https://doi.org/10.1002/ ptr.1637

[16] T.A. Van Beek, D. Joulain, The essential oil of patchouli, Pogostemon cablin: A review. Flavour Fragr. J. 33 (1) (2018) 6-51. DOI: https://doi.org/10.1002/FFJ.3418

[16] G. Hu, C. Peng, X. Xie, S. Zhang, X. Cao, Availability, Pharmaceutics, Security, Pharmacokinetics, and Pharmacological Activities of Patchouli Alcohol. Evidence-based Complement Altern. Med. 2017 (4) (2017) 1-9 . DOI: https://doi.org/10.1155/2017/4850612

[17] J. Zairi J, Y. Lee, Laboratory and field evaluation of household insecticide products and public health insecticides against vector mosquitoes rand house flies (Diptera: Culicidae, Muscidae). In: Proceedings of the Fifth International Conference on Urban Pests, 2005, pp. 477-482

[18] D.A Phal, R.H. Naik, K. Deobhankar, S. Vitonde, N. Ghatpande, Laboratory evaluation of herbal mosquito coils against Aedes aegypti Mosquito. Bull. Environ. Pharmacol. Life Sci. 1 (10) (2012) $16-20$

[19] J.T. Arnason, S.R.Sims, I.M. Sims, Natural Products from Plants as Insecticides. Encycl. Life Support Syst. 2010, 18 
[21] S. Marcombe, R.B. Mathieu, N. Pocquet, M.A. Riaz, R. Poupardin, S. Sélior, et al., Insecticide resistance in the dengue vector Aedes aegypti from martinique: Distribution, mechanisms and relations with environmental factors. PLoS One. 7 (2) (2012) e30989. DOI: https://doi.org/10.1371.journal.pone. 0030989

[20] P. Thangavel, G. Sridevi, Environmental sustainability: Role of green technologies. Springer, 2015, 324p 